IZA DP No. 4649

The Effectiveness of Regional Active Labour Market Policies to Fight against Unemployment: An Analysis for Catalonia

Raul Ramos

Jordi Surinach

Manuel Artís

December 2009 


\title{
The Effectiveness of Regional Active Labour Market Policies to Fight against Unemployment: An Analysis for Catalonia
}

\author{
Raul Ramos \\ $A Q R-I R E A$, Universitat de Barcelona \\ and IZA \\ Jordi Surinach \\ AQR-IREA, Universitat de Barcelona \\ Manuel Artís \\ $A Q R-I R E A$, Universitat de Barcelona
}

Discussion Paper No. 4649

December 2009

IZA

P.O. Box 7240

53072 Bonn

Germany

Phone: +49-228-3894-0

Fax: +49-228-3894-180

E-mail: iza@iza.org

Any opinions expressed here are those of the author(s) and not those of IZA. Research published in this series may include views on policy, but the institute itself takes no institutional policy positions.

The Institute for the Study of Labor (IZA) in Bonn is a local and virtual international research center and a place of communication between science, politics and business. IZA is an independent nonprofit organization supported by Deutsche Post Foundation. The center is associated with the University of Bonn and offers a stimulating research environment through its international network, workshops and conferences, data service, project support, research visits and doctoral program. IZA engages in (i) original and internationally competitive research in all fields of labor economics, (ii) development of policy concepts, and (iii) dissemination of research results and concepts to the interested public.

IZA Discussion Papers often represent preliminary work and are circulated to encourage discussion. Citation of such a paper should account for its provisional character. A revised version may be available directly from the author. 
IZA Discussion Paper No. 4649

December 2009

\section{ABSTRACT}

\section{The Effectiveness of Regional Active Labour Market Policies to Fight against Unemployment: An Analysis for Catalonia}

The aim of this work is to assess the effectiveness of active labour market policies carried out by the Catalan Public Employment Services (SOC) during the year 2005. The results obtained from the application of matching techniques show that the probability of finding a job for an individual who participated in any of the analyzed SOC's actions is 5 percentage points higher in relation to those who did not participate. The individual analysis of the different programs has shown the effectiveness of the greater part of the actions carried out. Last, the results have also highlighted the further improvement of the combination of some of the actions.

JEL Classification: C31, J64, J68

Keywords: $\quad$ active labour market policies, unemployment, propensity score matching

Corresponding author:

Raul Ramos

Department of Econometrics, Statistics and Spanish Economy

University of Barcelona

Avda. Diagonal 690

08034 Barcelona

Spain

E-mail:rramos@ub.edu 


\section{Background and aims ${ }^{1}$}

Data from EUROSTAT for 2005 show that the member states of the European Union (EU-15) spent 2.2\% of their GDP on implementing labour market policies. This figure ranged from $0.2 \%$ in Estonia to $4.1 \%$ in Denmark. In Spain, the amount spent on labour policies represented 2.1\% of its GDP, just slightly below the European mean.

Labour market policies include a set of relatively heterogeneous public actions and measures. Indeed, there would seem to be no generally accepted definition as to what should or should not be included within this package of policies. However, they typically include all those measures directed at the unemployed and the improvement of the job market, as well as measures that involve no public expenditure but which have a wide impact on the job market (including legislative changes that affect wage-setting mechanisms, the flexibility to hire and fire workers and the organisation of working hours).

Arguably the most widely accepted classification of labour market policies is that proposed by the OECD, which distinguishes between passive and active policies. The former are understood to be all those measures that seek to improve the situation of the unemployed and which try to guarantee them certain levels of income. By contrast, active policies are understood to be all those measures that seek to have a direct impact on the operation of the job market in terms of increasing labour demand (be it across the board or for just one specific group of workers that faces particular difficulties in finding work), but also those measures that seek to improve the adjustment processes between supply and demand in the labour market (for example, the organization of worker training programs, giving incentives to promote geographical mobility and improving channels of information between firms and workers).

As Fina and Toharia (2001) point out, the relative importance of these two types of policy has fluctuated over time depending on a range of factors, but primarily, on the

\footnotetext{
${ }^{1}$ The authors would like to thank the Catalan Employment Office (Servei d'Ocupació de Catalunya) for its help in constructing the database used here, and for its suggestions and comments regarding our work. Jordi Suriñach and Manuel Artís were supported by a grant received from the Ministry of Education via project ECO2009-12678. Any errors or omissions are the sole responsibility of the authors.
} 
phase of the business cycle reached by the economy being analysed, the health of its public finances and, above all, on the rate of unemployment at any particular time. In recent decades, active policies have acquired greater weight as passive policies do not seem to contribute to a reduction in unemployment but rather only help improve the situation of the unemployed until they find work. Indeed, the latter were designed to minimize the problems of unemployment when there were no great problems for finding work relatively quickly (frictional unemployment) and in a context when the public sector resources dedicated to these policies in times of recession are expected to be recovered in times of growth thanks to automatic stabilizers. In fact, today, in the EU-15 approximately $40 \%$ of the budget linked to labour market policies is spent on active policies, with the remaining $60 \%$ being dedicated to passive policies. Specifically, $0.8 \%$ of GDP in the EU-15 is spent on active policies. In Spain this figure stands at $0.7 \%$, while the country that dedicates the highest percentage of it resources to active policies is Holland with $1.6 \%$ of its GDP while the lowest percentage is recorded by Greece and Estonia at just $0.1 \%$.

Thus, active policies are born from the realization that at given moments the characteristics of the unemployed (their skills and geographical location) do not match those of the job vacancies, resulting in long-term or structural unemployment. Active labour market policies, therefore, seek to, improve training or to promote worker mobility to enhance their capacity to fill job vacancies. However, other types of active policy do aim to create new jobs, either through the direct creation of work in the public sector or the awarding of financial incentives (normally in the form of subsidies) linked to the creation of jobs which, at times, might be aimed at developing new production practices. Often this latter type of policy seeks to find work for specific groups of workers with particular problems. However, active policies of this kind have come in for considerable criticism as they are high cost and tend to be affected by opportunistic behaviour (deadweight effect), i.e., the subsidy is paid to create jobs that would have been created anyway. These policies can have other undesirable effects including those of substitution between different types of worker (subsidized vs. non-subsidized); those of expulsion, whereby subsidized firms obtain a competitive advantage with the result that non-subsidized firms lose their market share and have to shed labour; and those of wage pressure, since by reducing the costs of dismissal (to the extent that workers who lose their jobs will be sent on retraining programs), wage pressure increases and, 
therefore, employment can be negatively affected. Thus, depending on the relative importance of these effects, the impact on employment tends to be uncertain.

As Card et al. (2009) point out, the effectiveness of policies of this type has been the subject of intense debate in many countries. And, furthermore, the rigorous evaluation of data relating to participants and non-participants in active labour programs so as to quantify the effects of such policies is a procedure that should be carried out periodically by both the public administration and independent experts. In a recent study, for example, Kluve (2007) analyses more than a hundred different studies examining the impact of active labour policies by applying meta-analysis techniques.

By contrast, there have been very few microeconometric studies conducted in Spain, with the notable exceptions of Mato and Cueto (2009) and Arellano (2009) in the case of job training programs and Cansino and Sánchez (2009) in the case of vocational training programs (casas-taller and casas de oficio). These three studies report a positive effect on the unemployed that have participated on these programs: the first study shows that the job training program increases the probability of being in work by roughly 8 to $9 \%$, the second confirms the finding that training reduces the time spent out of work and the third shows the effectiveness of the program for the group for which it is designed, namely young people seeking their first job.

An important factor to bear in mind, when evaluating active labour market policies in Spain, is the process of decentralization that has occurred in this policy area in recent years. Thus, today each region or Autonomous Community has the power to determine the most suitable policies to adopt and the best way to implement them. Thus, the most suitable spatial level at which to analyse the impact of active policies is that associated with the normative power concerning these policies: namely, the Autonomous Community. Furthermore, even during the latest phase of expansion, the Spanish labour market has been characterized by a high degree of variation in its regional unemployment levels, a fact that might lead to even greater differences in the application of active labour market policies.

Against this background, the case of Catalonia is especially interesting since within this process of decentralization, it was the first to take charge of occupational training. This 
occurred in 1992 and it was, moreover, together with Galicia, one of the two communities where the transfer of the management of the state employment office INEM - became effective as early as January 1998, while the transfer to the other communities did not occur until later. Thus, the experience acquired by the Catalan autonomous authorities in this field has been greater than that of the other Autonomous Communities. Moreover, it has had the opportunity to introduce a greater number of programs and more varied instruments so that an evaluation of its policies should offer conclusions of interest for the design of active labour market policies in other Autonomous Communities.

Thus, the aim of this study is to evaluate the effectiveness of the active labour market policies promoted by the Catalan Labour Office (Servei d'Ocupació de Catalunya, henceforth SOC) during the year 2005 by applying microeconometric techniques.

The contribution of this study to the literature on this subject is two-fold: on the one hand, this is the first rigorous evaluation of several active labour market policies in Spain (and not just of one specific program) and, on the other, it analyses the ways in which some of these programs might complement each other. The results obtained from the application of matching techniques show that the probability of finding work for an individual who, in 2005, participated on one of the actions organized by SOC was 5 percentage points higher than those that did not participate.

The rest of this paper is structured in three parts: first, we present the database employed in conducting the study; second, we describe the methodology adopted and the results it provided; and, third, we summarize the main conclusions drawn from our analysis.

\section{Description of the database used}

The evaluation undertaken here has been facilitated by the availability of a broad database of individuals, which was previously made anonymous, and provided by SOC under the usual conditions of statistical secrecy. The SOC is responsible for virtually all active labour policies in Catalonia. Specifically, it undertakes three main lines of action - training, providing incentives and job advice, and it is organized in five main areas equal opportunities, job information and guidance, professional qualifications, work and 
training and job creation schemes. It is engaged in nine separate programs, which are described in greater detail below.

The database contains information regarding the socio-demographic characteristics of participants as well as non-participants in SOC actions during 2005. It also contains details regarding their work situation in December 2007 and January 2008, that is, between one and two years after participating on the programs. This is the reference variable for undertaking our evaluation. Specifically, we have access to data regarding the individuals' gender, age, schooling level, their municipality of residence, the type of action in which they participated and their current work status ${ }^{2}$.

According to this information, in 2005, there were 158,415 participants involved in SOC actions. As can be seen in Table 1, the programs with the greatest number of participants during that year were the regional employment pacts (48.7\%), the job training programs for the unemployed (27.0\%) and the personalized employment support programs (13.0\%). The regional pacts are innovative and experimental actions that complement active labour policies albeit without any specific normative regulations, and which seek to promote local development, serving as a means of coordinating active labour policies in a particular area. By contrast, the job training programs include a whole series of actions aimed at providing occupational training and the specific professional skills required for undertaking various jobs in which there is a need to incorporate more workers. Finally, the employment support programs are professional job guidance schemes aimed at providing personal support to the unemployed. Their aim is to encourage participation in activities that might improve an individual's job possibilities according to their specific professional and personal circumstances.

\section{TABLE 1}

In 2005 a fairly large percentage of workers participated in more than one SOC action during that twelve month period, actions which in virtually all cases corresponded to

\footnotetext{
${ }^{2}$ One shortcoming of the database is the fact that we are unable to obtain any information as to the participation or otherwise of the 2005 beneficiaries in additional actions undertaken in 2006 or 2007. This should be borne in mind when interpreting the results below.
} 
different programs. If we bear this fact in mind, the total number of participants was 123,889, of whom 109,606 participated in one single action (88.47\%), 12,790 in two $(10.32 \%)$ and the rest in more than two (1.21\%). While we are aware of this distinction, our analysis initially focuses on the beneficiaries of each action and not on the individuals themselves. In other words, we deal with the participants of each SOC action as if they had not participated in any other program. From our point of view, this procedure is appropriate, since within each action the number of participants that repeated the same action was virtually zero (i.e., we would not be counting the same individual more than once) and moreover, $82 \%$ of the individuals that participated in more than one action did so by combining a work program with the regional employment pacts, an action for which we do not have much information for many individuals regarding their main control variables, namely date of birth and the level of education - an additional motive for excluding this action from our analysis.

Table 2 shows the results of the descriptive analysis of the 77,862 individuals that participated in the SOC programs selected in 2005 (having first eliminated those individuals for whom all the necessary information was not available and those actions that represented fewer than $4 \%$ of the total participants). The information presented in this table has been complemented with the descriptors of the control group, comprising 730,871 individuals that did not participate in 2005 (nor before) in any SOC action. This table illustrates that the majority of the participants in SOC actions in 2005 were women (57.72\%), Spanish nationals (85.13\%), with an average age of 33.31 and a relatively low mean number of years of schooling (7.0). In the main, they were resident in the province of Barcelona (81.50\%), followed by Tarragona (8.74\%), Girona (5.62\%) and Lleida (3.82\%). We should also stress the large differences between programs, differences which, on the other hand, are expected bearing in mind the different nature and potential beneficiaries of the SOC actions. For example, there were notably fewer women in the vocational training workshops (casas-taller) and schools (casas de oficio), while their participants were notably younger. In fact, these two programs are oriented at this younger age group. Specifically, the vocational training workshops (casas-taller) seek to train and find employment for unemployed people below the age of 25, by alternating the acquisition of skills with work and professional practice acquired on specific projects undertaken in collaboration with non-profit, public and private entities. The participants are taught a skill over a maximum period of two years, 
while earning $75 \%$ of the minimum interprofessional wage while working on a local community project. They are also given the possibility of completing their compulsory secondary education, if they have not already done so. The vocational training schools (casas de oficio) are mixed training and work programs designed for people under the age of 25 who have completed their basic education, be it compulsory secondary education (ESO), baccalaureate, vocational training or any other form of training considered essential to undertake a specific job, but who have not acquired a practical level of knowledge or are lacking professional experience. Participation on these programs ensures, on the one hand, a good level of training, alternated with effective work experience, and, on the other, participation on a public or social project, managed by a range of entities. The programs run for a maximum of 12 months and the pay the participants receive varies over this period.

Likewise, the greater age of participants on the retraining (reciclaje) program is also understandable as its objective is to help individuals find work by providing them with, or perfecting, those professional skills they have lost in the workplace. This program is the only one in which the regional distribution of participants is not concentrated in the province of Barcelona but rather in Lleida.

\section{TABLE 2}

Finally, Table 3 compares the employment rate at the end of 2007/start of 2008 of participants on the programs analysed and non-participants. The comparison of these figures illustrates a difference in favour of the former of more than 6 percentage points (46.6\% compared to 40.5\%). A comparison by program highlights the effectiveness of public employment plans with a rate of almost 60\% (58.5\%), the job training programs for the unemployed (47.4\%), the personalized employment support programs (46.3\%) and the integrated actions (41.0\%), with rates higher than those reported by nonparticipants, while the retraining (reciclaje) program had a markedly lower rate (12.3\%). However, these results do not take into consideration the possible differences in the characteristics of the individuals that participated in the programs and those that did not, which is why it is necessary to apply econometric techniques that allow us to consider their possible impact on the probability of being employed. This analysis is conducted in the following section. 


\section{TABLE 3}

\section{Methodology and results}

\subsection{Evaluation of policies and matching techniques}

The aim of microeconometric policy evaluations typically involves responding to the question: What would have happened if this measure had not been implemented? In other words, in conducting a "counterfactual" analysis. In the specific case of labour market policies, it would involve assessing what the effect would be on a worker affected by a certain measure (for example, his or her participation in a training program) if they had not been affected by that measure (in other words, if he or she had not been on the program). In order to be able to evaluate the difference between the observed result and the counterfactual, the most usual approach involves comparing the situation of two groups of workers, one of which is affected by the measure and the other not. However, the main difficulty involves determining whether the improvement in the employment situation of the worker affected by the measure is a consequence of the measure itself or rather it is attributable to other factors that might often be unobservable. In other words, to what extent workers without a job who participated in a certain training program were not sufficiently motivated to find work before starting the program (selection bias).

The methodology adopted in the natural and health sciences involves random assignment experiments. In such experiments, individuals are assigned quite randomly into two groups: one of these will be affected by the political measure (for example, a job training program) while the other will not. A comparison of the results obtained by the individuals in the first group (the treatment group) with those obtained by the second (the control group) enables us to assess the effectiveness of the policy. However, there are serious drawbacks in applying this methodology to labour market polices: first, there are ethical issues that make it impossible to give or deny access to a training program to someone who is unemployed based solely on a random decision; second, the costs, both in terms of finance and of time, of organizing and monitoring adequately the two groups are very high; and, finally, the application of the measure could be severely 
delayed since the experiment would require a very careful design before applying the measure, and this delay could make it inappropriate or largely unnecessary when eventually adopted. Thus, the procedure we apply would be the only one possible when the measure we seek to evaluate is mandatory for the individuals affected (Cebulla, 2006).

Based on these arguments, the most usual approach for evaluating labour market policies involves the application of quasi-experimental methods (Rosenbaum, 1995). These methods are typically applied from two different perspectives, but both are based on the idea that once the measure has been applied, it is possible to conduct an ex-post analysis of the impact of the measure. The first approach involves comparing the situation of the individuals affected by the measure before and after, while the second involves identifying a posteriori individuals that did not participate in the programs evaluated so as to form a control group. The key to this second procedure involves identifying individuals who resemble as closely as possible those affected by the measure both in terms of their observable and unobservable characteristics, a process which in practice is very complicated. Thus, the possible presence of selection bias affects the reliability of the results obtained when using this procedure.

Here, to evaluate active labour policies, we apply matching techniques or, more specifically, propensity score matching (PSM). This algorithm allows us to select from the control group of persons that did not participate in the programs that we seek to evaluate, those with the same propensity to participate on the program as those that actually did (Smith and Todd, 2005). In this way, we avoid the selection bias problem: that is, the fact that the persons who participate in the programs are those with better skills and aptitudes for finding work among all individuals without work ${ }^{3}$. Specifically, the main assumption is that the selection bias is eliminated once we have controlled for a set of observable variables. Therefore, it is supposed that the result for a certain variable $D$ (for example, work status) would be the same for participants $\left(Y^{1}\right)$ and nonparticipants $\left(Y^{0}\right)$, once we have controlled for a set of variables $X$ (such as gender, age, schooling level, etc.):

\footnotetext{
${ }^{3}$ For further details, see Durán (2004.)
} 


$$
\operatorname{Pr}\left[D=1 / Y^{0}, Y^{1}, X\right]=\operatorname{Pr}[D=1 / X]
$$

This equality holds provided that the assumption of conditional independence also holds, that is, that $D$ and $Y^{0}$ are independent for each value of $X$ or, in other words, that the participation in the program is independent of the result obtained by those that do not participate on the program. A further relevant aspect is that of dimensionality, that is, the possibility of finding a non-participant with exactly the same characteristics as those of a participant. To overcome this problem, Rosenbaum and Rosen (1983) proposed analysing the propensity score instead of the probability. The results presented below are based on these assumptions.

\subsection{Results}

In order to apply propensity score matching, the first step involves estimating a logit model for the probability of being employed or otherwise using as explanatory variables the observable characteristics of the individual (nationality, gender, age, schooling and province of residence), which allows us to obtain the propensity score for each individual to be participant or non-participant. Then, we need to link each participant with a non-participant based on a comparison of their observable characteristics. Thus, to implement the applied algorithm we need to decide on the number of non-participants that is to be used as the group of reference for each participant and what criteria will be used to find it. The results presented below were obtained by applying the procedure based on the nearest neighbour with random assignment and a proportion of participants to non-participants of 2:1. The results do not vary greatly if we apply other criteria (radius, caliper, etc.) and different proportions (5:1 and 10:1) ${ }^{4}$.

Table 4 shows the mean estimated effect of having participated in the various actions organized by SOC during 2005 as well as the effect on all participants, ignoring the fact that an individual might have participated in more than one action ${ }^{5}$. The first column

\footnotetext{
${ }^{4}$ All calculations were made using the psmatch2 procedure for STATA (Leuven and Sianesi, 2006). The results of the sensitivity analysis are available on request from the authors.

${ }^{5}$ Before applying the matching techniques, a probit model was specified and estimated for the probability of being employed at the end of 2007/start of 2008. The advantage of this type of specification over a descriptive analysis lies in the fact that it allows to control for the differences in the observable characteristics of the individuals (nationality, sex, age, schooling and province of residence). According to this model, having participated in the SOC programs during 2005 would increase the probability of
} 
shows the percentage of individuals employed at the end of 2007/beginning of 2008 as a function of the SOC program in which they participated. The second column, by contrast, shows what the probability would have been of these individuals being employed if they had not participated on the program (counterfactual analysis). This

probability is calculated by combining the information concerning the characteristics of the participants with that of the individuals in the control group that present the same propensity to participate in the programs. The third column shows the difference between the first and second columns; in other words, the change in probability of being employed as a consequence of having participated in the actions analysed. The fourth column shows the statistical value of the hypothesis test whose null hypothesis is that the effect of participating in the program is 0 as opposed to the alternative hypothesis whose value differs from 0 , while the fifth column shows the p-value (the significance level that has to be fixed in order to reject the null hypothesis).

\section{TABLE 4}

For those participating in one of the SOC actions (last row in the table), the percentage of individuals in work at the end of 2007/start of 2008 was $47.48 \%$. And, according to the counterfactual analysis, if these individuals had not participated in the SOC programs, this percentage would have been $42.45 \%$. Therefore, the difference between the two is $5.03 \%(47.48 \%-42.45 \%)$. This figure implies that the probability of finding a job for an individual that participated in one of the 2005 SOC actions analysed here rose by 5 percentage points as a direct result of their having participated. Furthermore, the statistical value of the hypothesis test and its associated p-value allow us to reject the null hypothesis that the effect detected is equal to 0 .

If we focus on the effect of the various programs, we observe that for the integrated actions, the personalized employment support programs, the job training for the unemployed and the public employment plans, the effect of participating in the SOC actions is positive and significant. This effect varies between $17.9 \%$ for the public

being employed by $6.2 \%$. When analysed by programs, we obtain positive and significant effects at the usual levels of significance in virtually all cases (the exceptions being the social protection programs, the vocational training schools and the retraining program), but it should be borne in mind that this approach does not overcome the selection bias, which might have a considerable impact on the results obtained. The results are available on request from the authors. 
employment plans and $4.4 \%$ for the integrated actions. Note that there are three cases in which the effect of having participated on the SOC programs is not statistically different from 0 at the usual levels of significance (0.05 and 0.1). Specifically, these are the social protection program, the vocational training programs (casas-taller) and schools (casas de oficio). It is likely that in these three programs, and because of their very nature, the beneficiaries are still undergoing training two years after having participated (their ages being around 16-17 in 2005). Finally, there is one case where participating had a negative and significant effect. This was the retraining (reciclaje) program. According to the results shown in Table 4, the probability of being employed two years after having participated in the program was no more than $4.7 \%$. This result could be related to the "lock-in" effect of individuals without work. The belief is that these persons might tend to continue receiving training once the initial program has finished and, therefore, reduce the intensity with which they seek work.

An additional aspect which should be analysed when an algorithm such as the propensity score matching is applied is the quality of the matching between participants and non-participants. Specifically, we need to ascertain the extent to which we have found a group of individuals similar to that of the participants among the nonparticipants. One way of verifying this is by calculating the reduction in the bias for each of the control variables that intervene in the algorithm between the total participants and the non-participants and those non-participants selected as the reference group. For each of the variables used to identify the non-participants most similar to the participants (nationality, gender, age, schooling), Table 5 shows the percentage of individuals in each category (for example, in the first row the percentage of Spaniards) and arithmetic mean (in the case of age) before matching and after matching both for the participants and for the control group. The values for the participants are the same but for the control group they are different. Specifically, the quality of matching is better the closer the control resembles participants after matching. The difference between the two groups is the bias and the last column shows the reduction in this bias after matching. As can be seen before matching, the bias (as an absolute value) is quite high for some of the variables. For example, before matching, the mean age of the participants is 33.12 while that of the non-participants is 37.75 , a bias of $37.4 \%$. By contrast, following matching, the bias is reduced to $0.2 \%$, which implies a reduction of almost $100 \%$. As can be seen in the table, the percentage reductions are high and the 
bias following matching is, in all instances, below 5\%, which guarantees the reliability of the results presented up to this point.

\section{TABLE 5}

As discussed in the first section above, an additional objective of this study was to assess the extent to which the policies analysed were complementary. As can be seen in Table 6, of the 71,625 individuals for whom we evaluated the efficacy of the SOC policies, 5,871 had participated in more than one program, representing $8.2 \%$ of the total $^{6}$. Of these individuals, $94.3 \%$ participated in just two programs. Here, it is important to point out that given the design of the SOC actions, in many cases it is not possible to participate in more than one program (for example, the unemployed workers on the vocational training programs, the casas-taller). Indeed, Table 7 shows that the combination of two programs was relatively infrequent in 2005. . In fact, the only combination of any great importance in absolute terms occurred on the job training programs for the unemployed and the personalized employment support programs with 2,399 individuals. This figure is clearly greater than the rest of the combination of programs and represents around $45 \%$ of all the individuals that participated on more than one of the actions selected for 2005. In fact, the number of individuals that participated in each of the combinations of the remaining actions is markedly lower and was not sufficient to be able to apply the matching techniques presented in the sections above with adequate reliability.

\section{TABLES 6 and 7}

Therefore, we analysed whether the effectiveness of the combination of these two policies (training programs for the unemployed and the personalized employment support programs) was greater than that recorded by those who had only participated on one of the two programs. The fact that the number of participants that participated simultaneously on the two actions was relatively small in relation to the total number participating on each program (5.67\% for training programs for the unemployed and

\footnotetext{
${ }^{6}$ Here, it should be borne in mind that overall the program that was most often recorded in combination with another action was that of the regional employment pacts which have not been evaluated owing to the high number of missing data.

${ }^{7}$ Table 7 only shows those combinations where the number of participants rose above fifty.
} 
$11.40 \%$ for the personalized employment support programs) allows us to establish as a control group the remaining participants on each of the actions being evaluated. One of the first findings to highlight is that the rate of employment of the individuals that participated on the two programs was $53.85 \%$ compared to $47.33 \%$ for those who participated only on the training programs for the unemployed and $45.93 \%$ for those who did so only on the personalized employment support programs. It seems therefore that participating on the two programs was more effective than just participating on one. To confirm this, we applied the matching techniques described above for each of the two programs. Table 8 shows the results obtained. As can be seen, these results confirm the greater effectiveness of the combination of policies compared to having participated in just one program. This effect is around $8 \%$ for the training programs for the unemployed and $9 \%$ for the personalized employment support programs, which confirms the complementary nature of the two programs analysed.

TABLE 8.

\section{Final considerations}

The aim of this study was to evaluate the effectiveness of the active labour policies implemented by the Catalan Employment Office (SOC) in 2005. Our results, derived from the application of matching techniques, allow us to conclude that the probability of finding work in the case of an individual that participated during that year on one of the actions organized by SOC was 5 percentage points higher than that of someone who did not participate - and this being a consequence of their having participated in a SOC program. We also found evidence regarding the positive effect of most of the programs implemented, as well as the existence of differences between actions and an enhanced probability of finding employment among those participating in two or more programs. In fact, our analysis of the complementary nature of different actions might be extended in the future so as to determine whether there are differences in impact according to the sequence in which individuals participate on the programs analysed (see, for example, Lechner and Wieler, 2007).

Finally, and while the results are of great interest to those with the task of designing labour market policies, an additional conclusion that can be drawn from the study is that 
there are still various aspects that require an additional effort from government bodies when it comes to establishing protocols for gathering statistical information that permit the periodic evaluation of their policies. Specifically, in the first place, there is a need to take further steps towards analysing the efficiency of these policies (and not just their effectiveness). Second, there is a need to analyse specific job conditions, including number of working hours, contract conditions, wages, etc. both for participants and nonparticipants in active policies. We believe these two aspects must be considered if we wish to undertake similar evaluations to those being made in other countries in this region of Europe.

\section{References}

Arellano, F. A. (2009), "Do training programs get the unemployed back to work? A look at the Spanish experience”, Revista de Economía Aplicada, forthcoming.

Cansino, J. M., Sánchez, A. (2009), "Evaluación del programa de escuelas-taller y casas de oficio a partir de su efecto sobre el tiempo de búsqueda del primer empleo. El caso de Sevilla“, Estudios de Economía Aplicada, 27 (1), pp. 1-22.

Card, D., Kluve, J., Weber, A. (2009), “Active Labor Market Policy Evaluations - A Meta-analysis”, Ruhr Economic Papers 86.

Cebulla, A. (2006), Meta-Analysis of US welfare-to-work programs - approach, problems and lessons, National Centre for Social Research, London.

Duran, C. (2004), "Evaluación microeconométrica de las políticas públicas de empleo: aspectos metodológicos”, Hacienda Pública Española / Revista de Economía Pública, 170 (3-2004), pp. 107-133.

Fina, L., Toharia, L (2001), El reto del empleo, Editorial McGraw-Hill.

Kluve, J. (2007), “The Effectiveness of European ALMP’s”, a Kluve, J. et al. (eds.), Active Labor Market Policies in Europe: Performance and Perspectives, Springer, Berlin and Heidelberg, pp. 153-203.

Lechner, M., Wieler, S. (2007), Does the Order and Timing of Active Labor Market Programs Matter?, IZA Discussion Paper 3092.

Leuwen, E., Sianesi, B. (2006), "PSMATCH2: Stata module to perform full Mahalanobis and propensity score matching, common support graphing, and covariate imbalance testing”, http://ideas.repec.org/c/boc/bocode/s432001.html.

Mato, J., Cueto, B. (2009), “A nonexperimental evaluation of training programs: regional evidence for Spain”, Annals of Regional Science, 43, pp. 415-433

Rosembaum, P. R. (1995), Observational studies, Springer-Verlag, Nova York.

Rosenbaum P. R.. Rubin, D. B. (1983), “The central role of the propensity score in observational studies for causal effects”, Biometrika 70(1), pp. 41-55.

Smith, J. A., Todd, P. (2005), Does matching overcome LaLonde's critique of nonexperimental estimators?, Journal of Econometrics, 125: 305-353. 


\section{Tables and figures}

Table 1. Number of participants in SOC's actions during 2005

\begin{tabular}{llcc} 
Area & Program & \multicolumn{2}{c}{ Participants } \\
\hline A Equal opportunities & Integrated actions & 2,500 & $1.6 \%$ \\
B Job information and guidance & Personalized employment support & 21,399 & $13.5 \%$ \\
C Professional qualification & Job training for unemployed & 42,768 & $27.0 \%$ \\
& Social guarantee programs & 1,910 & $1.2 \%$ \\
& Retraining & 2,625 & $1.7 \%$ \\
D Work and training & Casas de oficio & 1,534 & $1.0 \%$ \\
& Escuelas taller & 1,690 & $1.1 \%$ \\
E Job creation schemes & Regional employment pacts & 77,166 & $48.7 \%$ \\
& Public employment plans & 6,823 & $4.3 \%$ \\
\hline Total & & 158,415 & $100.0 \%$ \\
\hline
\end{tabular}


Table 2. Descriptive analysis of participants and non-participants in 2005 SOC's selected actions

\begin{tabular}{|c|c|c|c|c|c|c|c|c|c|c|}
\hline & & Observations & \% Spaniards & \%Female & Average age & Schooling years & \% Barcelona & \% Girona & \% LLeida & \% Tarragona \\
\hline \multirow{10}{*}{ 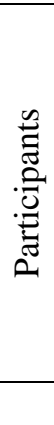 } & Integrated actions & 2462 & $64.8 \%$ & $45.5 \%$ & 28.9 & 5.8 & $75.2 \%$ & $7.4 \%$ & $3.0 \%$ & $14.3 \%$ \\
\hline & Personalized employment support & 21035 & $88.7 \%$ & $61.1 \%$ & 36.0 & 7.0 & $78.6 \%$ & $6.5 \%$ & $4.3 \%$ & $10.5 \%$ \\
\hline & Job training for unemployed & 42321 & $88.5 \%$ & $64.4 \%$ & 33.7 & 7.0 & $78.4 \%$ & $7.3 \%$ & $4.2 \%$ & $10.1 \%$ \\
\hline & Social guarantee programs & 1882 & $78.6 \%$ & $41.0 \%$ & 17.0 & 5.8 & $84.0 \%$ & $2.9 \%$ & $1.7 \%$ & $11.4 \%$ \\
\hline & Retraining & 806 & $96.4 \%$ & $31.3 \%$ & 35.1 & 7.8 & $25.9 \%$ & $9.8 \%$ & $41.6 \%$ & $22.7 \%$ \\
\hline & Casas de oficio & 1500 & $62.7 \%$ & $13.0 \%$ & 17.4 & 5.7 & $70.8 \%$ & $7.6 \%$ & $5.9 \%$ & $15.7 \%$ \\
\hline & Escuelas taller & 1611 & $74.9 \%$ & $8.7 \%$ & 19.1 & 6.0 & $79.8 \%$ & $13.7 \%$ & $3.5 \%$ & $3.0 \%$ \\
\hline & Public employment plans & 6245 & $98.2 \%$ & $42.7 \%$ & 32.4 & 7.5 & $57.3 \%$ & $9.1 \%$ & $15.8 \%$ & $17.8 \%$ \\
\hline & Total & 77862 & $87.6 \%$ & $58.1 \%$ & 33.1 & 7.0 & $76.1 \%$ & $7.3 \%$ & $5.5 \%$ & $11.1 \%$ \\
\hline & Non participants & 730871 & $85.0 \%$ & $52.6 \%$ & 37.7 & 7.2 & $73.6 \%$ & $9.8 \%$ & $5.3 \%$ & $11.2 \%$ \\
\hline
\end{tabular}


Table 3. Employment rate of participants and non-participants in 2005 SOC's selected actions

\begin{tabular}{|c|c|c|c|}
\hline & & Observations & Employment rate \\
\hline \multirow{10}{*}{ 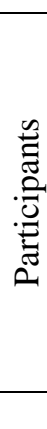 } & Integrated actions & 2462 & $41.3 \%$ \\
\hline & Personalized employment support & 21035 & $46.8 \%$ \\
\hline & Job training for unemployed & 42321 & $47.8 \%$ \\
\hline & Social guarantee programs & 1882 & $32.1 \%$ \\
\hline & Retraining & 806 & $39.8 \%$ \\
\hline & Casas de oficio & 1500 & $36.3 \%$ \\
\hline & Escuelas taller & 1611 & $36.0 \%$ \\
\hline & Public employment plans & 6245 & $63.4 \%$ \\
\hline & Total & 77862 & $47.5 \%$ \\
\hline & Non participants & 730871 & $40.5 \%$ \\
\hline
\end{tabular}

Table 4. Effectiveness of 2005 SOC's selected actions

\begin{tabular}{lccccc} 
& $\begin{array}{c}\text { Observed } \\
\text { (participating) }\end{array}$ & $\begin{array}{c}\text { Counterfactual } \\
\text { (without participating) }\end{array}$ & Difference & T-stat & P-value \\
\hline Integrated actions & $41.35 \%$ & $36.94 \%$ & $4.41 \%$ & 2.26 & 0.01 \\
Personalized employment support & $46.83 \%$ & $40.91 \%$ & $5.92 \%$ & 3.25 & 0.00 \\
Job training for unemployed & $47.76 \%$ & $41.88 \%$ & $5.88 \%$ & 4.26 & 0.00 \\
Social guarantee programs & $32.09 \%$ & $27.05 \%$ & $5.05 \%$ & 0.65 & 0.26 \\
Retraining & $39.83 \%$ & $44.54 \%$ & $-4.71 \%$ & -1.98 & 0.02 \\
Casas de oficio & $36.33 \%$ & $30.60 \%$ & $5.73 \%$ & 0.89 & 0.19 \\
Escuelas taller & $36.00 \%$ & $39.39 \%$ & $-3.38 \%$ & -0.53 & 0.30 \\
Public employment plans & $63.39 \%$ & $45.49 \%$ & $17.90 \%$ & 9.64 & 0.00 \\
\hline Total (no “duplicities") & $47.48 \%$ & $42.45 \%$ & $5.03 \%$ & 3.67 & 0.00 \\
\hline
\end{tabular}


Table 5. Analysis of the quality of the matching

\begin{tabular}{|c|c|c|c|c|c|}
\hline Variable & Sample & Participants & Control & $\%$ Bias & $\%$ Reduction \\
\hline \multirow{2}{*}{ Spaniard } & Before & $87.8 \%$ & $85.0 \%$ & 8.1 & \\
\hline & After & $87.8 \%$ & $87.1 \%$ & 2.1 & 74.5 \\
\hline \multirow[t]{2}{*}{ Non Spaniard } & Before & $12.2 \%$ & $15.0 \%$ & -8.1 & \\
\hline & After & $12.2 \%$ & $12.9 \%$ & -2.1 & 74.5 \\
\hline \multirow[t]{2}{*}{ Male } & Before & $58.3 \%$ & $52.6 \%$ & 11.5 & \\
\hline & After & $58.3 \%$ & $57.9 \%$ & 0.7 & 93.5 \\
\hline \multirow[t]{2}{*}{ Female } & Before & $41.7 \%$ & $47.4 \%$ & -11.5 & \\
\hline & After & $41.7 \%$ & $42.1 \%$ & -0.7 & 93.5 \\
\hline \multirow[t]{2}{*}{ Age } & Before & 33.12 & 37.75 & -37.4 & \\
\hline & After & 33.12 & 33.09 & 0.2 & 99.3 \\
\hline \multirow[t]{2}{*}{ No schooling } & Before & $8.3 \%$ & $11.5 \%$ & -10.8 & \\
\hline & After & $8.3 \%$ & $8.2 \%$ & 0.2 & 98.2 \\
\hline \multirow[t]{2}{*}{ Unfinished primary studies } & Before & $34.4 \%$ & $29.8 \%$ & 9.9 & \\
\hline & After & $34.4 \%$ & $34.1 \%$ & 0.6 & 94.3 \\
\hline \multirow[t]{2}{*}{ Primary studies } & Before & $7.4 \%$ & $3.2 \%$ & 18.6 & \\
\hline & After & $7.4 \%$ & $8.0 \%$ & -2.7 & 85.7 \\
\hline \multirow[t]{2}{*}{ Secondary studies (lower) } & Before & $5.6 \%$ & $7.9 \%$ & -9.1 & \\
\hline & After & $5.6 \%$ & $5.7 \%$ & -0.2 & 97.5 \\
\hline \multirow[t]{2}{*}{ Occupational training ( $1^{\text {st }}$ stage) } & Before & $11.2 \%$ & $6.3 \%$ & 17.3 & \\
\hline & After & $11.2 \%$ & $11.3 \%$ & -0.5 & 96.9 \\
\hline \multirow[t]{2}{*}{ Occupational training ( $2^{\text {nd }}$ stage) } & Before & $28.0 \%$ & $30.7 \%$ & -5.8 & \\
\hline & After & $28.0 \%$ & $27.3 \%$ & 1.5 & 74.2 \\
\hline \multirow[t]{2}{*}{ Secondary studies (upper) } & Before & $0.2 \%$ & $0.7 \%$ & -6.7 & \\
\hline & After & $0.2 \%$ & $0.3 \%$ & -1.9 & 72.6 \\
\hline \multirow[t]{2}{*}{ University studies ( $1^{\text {st }}$ stage) } & Before & $2.0 \%$ & $4.1 \%$ & -12.7 & \\
\hline & After & $2.0 \%$ & $2.0 \%$ & -0.1 & 99.4 \\
\hline \multirow[t]{2}{*}{ University studies ( $2^{\text {nd }}$ stage) } & Before & $2.9 \%$ & $5.8 \%$ & -13.9 & \\
\hline & After & $2.9 \%$ & $3.0 \%$ & -0.1 & 99.2 \\
\hline \multirow[t]{2}{*}{ University studies (post-graduate) } & Before & $0.0 \%$ & $0.1 \%$ & -1.5 & \\
\hline & After & $0.0 \%$ & $0.1 \%$ & -1.8 & -14.8 \\
\hline
\end{tabular}


Table 6. Number of participants in 2005 SOC's selected actions according to the number of programs they have participated

\begin{tabular}{crr} 
Number of programs & \multicolumn{2}{c}{ Participants } \\
\hline 1 & 65,754 & $91.8 \%$ \\
2 & 5,541 & $7.7 \%$ \\
3 & 298 & $0.4 \%$ \\
4 & 30 & $0.0 \%$ \\
6 & 2 & $0.0 \%$ \\
\hline Total & 71,625 & $100.0 \%$
\end{tabular}

Table 7. Main combination of 2005 SOC's selected actions

Program 1

Job training for unemployed

Job training for unemployed

Integrated actions

Integrated actions

Personalized employment support programs

Personalized employment support programs

Job training for unemployed
Program 2

Personalized employment support programs 2399

Public employment plans 194

Job training for unemployed $\quad 172$

Personalized employment support programs 161

Public employment plans 157

Social guarantee programs 99

Social guarantee programs $\quad 80$

Table 8. Effectiveness of combining 2005 SOC's selected actions

\begin{tabular}{lccccc} 
& $\begin{array}{c}\text { Observed } \\
\text { (participating) }\end{array}$ & $\begin{array}{c}\text { Counterfactual } \\
\text { (without participating) }\end{array}$ & Difference & T-stat & P-value \\
\hline Job training for unemployed & $53.86 \%$ & $46.12 \%$ & $7.73 \%$ & 3.72 & 0.00 \\
Personalized employment support programs & $53.86 \%$ & $44.98 \%$ & $8.88 \%$ & 2.28 & 0.01 \\
\hline
\end{tabular}

